\title{
Sex-associated Treatment Differences and Their Outcomes in Rheumatoid Arthritis: Results from the METEOR Register
}

\author{
Sytske Anne Bergstra, Cornelia F. Allaart, Sofia Ramiro, Arvind Chopra, Nimmisha Govind, \\ Cândida Silva, Elizabeth A. Murphy, and Robert B.M. Landewé
}

\begin{abstract}
Objective. To assess differences in initial treatment and treatment response in male and female patients with rheumatoid arthritis (RA) in daily clinical practice.

Methods. The proportion of patients with RA starting different antirheumatic treatments (disease-modifying antirheumatic drugs; DMARD) and the response to treatment were compared in the international, observational METEOR register. All visits from start of the first DMARD until the first DMARD switch or the end of followup were selected. The effect of sex on time to switch from first to second treatment was calculated using Cox regression. Linear mixed model analyses were performed to assess whether men and women responded differently to treatments, as measured by Disease Activity Score (DAS) or Health Assessment Questionnaire.

Results. Women $(n=4393)$ more often started treatment with hydroxychloroquine, as monotherapy or in combination with methotrexate (MTX) or a glucocorticoid, and men $(n=1142)$ more often started treatment with MTX and/or sulfasalazine. Time to switch DMARD was shorter for women than for men. Women had a statistically significantly higher DAS over time than men (DAS improvement per year $\beta-0.69,95 \% \mathrm{CI}-0.75$ to -0.62 for men and $-0.58,95 \% \mathrm{CI}-0.62$ to -0.55 for women). Subanalyses per DMARD group showed for the conventional synthetic DMARD combination therapy a slightly greater decrease in DAS over time in men $(-0.89,95 \% \mathrm{CI}-1.07$ to -0.71$)$ compared to women $(-0.59,95 \%$ CI -0.67 to -0.51$)$, but these difference between the sexes were clinically negligible.

Conclusion. This worldwide observational study suggests that in daily practice, men and women with RA are prescribed different initial treatments, but there were no differences in response to treatment between the sexes. (First Release June 15 2018; J Rheumatol 2018;45:1361-6; doi:10.3899/ jrheum.171176)
\end{abstract}

\section{Key Indexing Terms: RHEUMATOID ARTHRITIS DISEASE-MODIFYING ANTIRHEUMATIC DRUGS HEALTH ASSESSMENT QUESTIONNAIRE SISEASE ACTIVITY SEX}

The prevalence of rheumatoid arthritis (RA) is higher in women than in men, with at least a 3:1 ratio for women compared to men ${ }^{1}$. Men may have a different RA phenotype than women, with a later age of onset and a higher percentage of autoantibody positivity ${ }^{2}$. Genetic and hormonal differences and behavioral factors (e.g., smoking) have been suggested to underlie these sex differences ${ }^{3,4,5,6}$.

From the Leiden University Medical Center (LUMC), Leiden; Amsterdam Rheumatology and Immunology Center, Amsterdam; Zuyderland Medical Center, Heerlen, the Netherlands; Center for Rheumatic Diseases, Pune, India; University of the Witwatersrand, Johannesburg, South Africa; Instituto Português de Reumatologia, Lisbon, Portugal; Wishaw General Hospital, Wishaw, Lanarkshire, UK

S.A. Bergstra, MSc, LUMC; C.F. Allaart, MD, PhD, LUMC; S. Ramiro, $M D, P h D, L U M C$; A. Chopra, $M D, P h D$, Center for Rheumatic Diseases; $N$. Govind, MD, University of the Witwatersrand; C. Silva, MD, Instituto Português de Reumatologia; E.A. Murphy, MD, Wishaw General Hospital; R.B. Landewé, MD, PhD, Amsterdam Rheumatology and Immunology Center, and Zuyderland Medical Center.

Address correspondence to S.A. Bergstra, Leiden University Medical Center, Rheumatology, Albinusdreef 2, Leiden, 2333 ZA, the Netherlands. E-mail: s.a.bergstra@lumc.nl

Accepted for publication February 28, 2018.
In the past, when treatment possibilities were limited and higher disease activity was common, RA resulted in unfavorable outcomes in many patients, and potential sex differences were considered irrelevant. New treatment options and strategies have optimized treatment outcomes. While women and men appear to have similar disease activity levels at presentation, the outcomes of RA treatment may still differ: men, for instance, are more likely to reach low disease activity and (drug-free) remission, while women report more pain and worse functional ability ${ }^{5,7-12}$. Individually tailored (i.e., personalized) treatment should ensure that the treatment for a patient be chosen so that the best clinical response will be obtained at the earliest possible time, resulting in the highest benefit. In such a strategy, it may be relevant to consider that male and female patients may have different treatment needs. They may, for instance, respond differently to different treatment strategies, but prescribing physicians may also have different perceptions about the urgency of effective treatment in men versus women, and the likelihood of a favorable response to a particular treatment.

Personal non-commercial use only. The Journal of Rheumatology Copyright @ 2018 . All rights reserved. 
Our research question was to investigate whether rheumatologists make different treatment choices in male and female patients, and whether male and female patients respond differently to the prescribed treatment.

\section{MATERIALS AND METHODS}

Data selection. Data were derived from the Measurement of Efficacy of Treatment in the Era of Outcome in Rheumatology (METEOR), an international observational register recording daily clinical practice. METEOR is not an inception cohort but includes data of all patients with RA visiting a rheumatologist. Data are entered through upload from existing electronic health record systems or registers or by using the free online METEOR tool. Because the register contains data collected in daily clinical practice, the number of visits and the frequency of followup visits differed among patients. At the first visit, several patient and disease characteristics are entered [e.g., year of birth, sex, rheumatoid factor (RF) and anticitrullinated protein antibodies (ACPA) status], and during followup visits, data on disease activity, medication, and physical functioning are gathered, all according to regular care. METEOR has been described extensively before ${ }^{13}$. Data in METEOR were gathered anonymously and recorded only daily clinical practice; hence, medical ethics committee approval was not required. To investigate the response to the first antirheumatic treatment [conventional synthetic disease-modifying antirheumatic drugs (csDMARD) and/or oral or parenteral glucocorticoids (GC)], we selected data of all patients who fulfilled the following criteria: symptom duration $<5$ years, medication start within 3 months after diagnosis of RA according to the treating rheumatologist, baseline Disease Activity Score (DAS) $\geq 1.6$, available data regarding medication use at baseline and followup, and at least 1 visit with available composite disease activity measure (e.g., 28-joint DAS, Simplified Disease Activity Index, Clinical Disease Activity Index). All available followup visits were selected from the start until the first switch in antirheumatic medication, or until the end of followup. A medication switch was defined as either a change in type of drug [e.g., from methotrexate (MTX) to leflunomide] or the addition of a new drug (e.g., from MTX to MTX + prednisone), but does not include changes in the dose of the current medication or tapering of treatment (e.g., from combination therapy with MTX + prednisone to MTX monotherapy, or tapering to drug-free remission).

Outcome measures. Time to switch medication (i.e., the time to decide that the first antirheumatic treatment had failed), was used as an efficacy measure, which was compared between males and females.

Response to the first antirheumatic treatment was measured by the DAS ${ }^{14}$ and the Health Assessment Questionnaire (HAQ) ${ }^{15}$. Response to treatment was measured over time, taking all available visits into consideration.

Treatment groups. Initiated medications were first divided into 5 treatment groups: (1) csDMARD monotherapy; (2) csDMARD combination therapy; (3) a single csDMARD with a GC; (4) combination therapy with $>1$ csDMARD and GC; and (5) GC monotherapy. Additional analyses were performed for individual medication combinations.

Statistical analyses. The proportion of patients starting the different medication strategies across sexes was compared at baseline. A Cox regression analysis was performed with the time to switch from the first to the second treatment strategy (as proxy for treatment failure) as outcome. Patients were censored when they switched treatment, or at the end of available followup. Sex was added as predictor and analyses were adjusted for potential confounders. We considered age, RF, ACPA, country, year of first visit, symptom duration at diagnosis, body mass index (BMI), smoking, and disease activity as potential confounders and performed linear regression analyses to assess whether these potential confounders were associated with the predictor sex. Each of these variables that was associated with sex $(p<0.20)$ was added as a confounder. Next, linear mixed model analyses were performed to assess whether men and women responded differently to treatment over time, as measured by DAS and HAQ. First, a general effect of sex on treatment response was calculated for all selected patients, by adding sex, followup time, and the interaction between sex and followup time to the model. In the presence of a significant interaction $(\mathrm{p}<0.10)$, analyses were stratified by sex. Subsequently, subgroup analyses were performed by treatment group and then by individual medication combinations, for medication combinations that were given to at least 100 patients. In these subgroups, the same analyses with the interaction term between followup time and sex were conducted. Analyses were adjusted for potential baseline confounders as described above, except for DAS, because this was the outcome of the analysis. To account for irregular time intervals, random intercept and random slope were added to each model, assuming an "exchangeable" covariance matrix.

Further, effect modification by country was tested by adding an interaction term between sex, time in followup, and country, and effect modification by age was tested by adding an interaction term between sex, time in followup, and dichotomized age (age $<50$ and $\geq 50$ ). If these interaction terms were nonsignificant, analyses were performed for all countries and both age categories together, and country and age were only added as potential confounders. $\mathrm{P}$ values $<0.05$ were considered statistically significant.

Missing data regarding disease activity, $\mathrm{HAQ}$, age, BMI, smoking, RF, and ACPA were imputed using additional information on sex, time in followup, country, medication, symptom duration, and year of first visit, using multivariable normal imputation (30 imputations) ${ }^{16}$. All analyses were performed using Stata SE version 14 (StataCorp LP).

\section{RESULTS}

Baseline characteristics and initial treatment. From the 36,576 patients included in the METEOR database, data of 5820 patients fulfilled the inclusion criteria of our current study (Supplementary Figure 1, available with the online version of this article). Of these, 1142 men and 4393 women fulfilled the selection criteria for available data and could thus be included in the current analyses. A flowchart of the selection process and a comparison of baseline characteristics of included and non-included patients are presented in Supplementary Figure 1 and Supplementary Table 1 (available with the online version of this article). Non-included patients had slightly longer symptom duration at diagnosis but were otherwise mostly similar to included patients. Baseline characteristics of the included patients are shown in Table 1. The median time (interquartile range; IQR) in followup was 15.3 months (IQR 8.1-31.3) for men and 15.3 months (IQR 6.7-35.7) for women, with a median of 4 visits (IQR 3-7) for both men and women. On average, women were slightly younger and slightly more often RF- and/or ACPA-positive, had longer symptom duration and higher disease activity compared to men, and fewer of them smoked compared to men. Initial medication for men and women is presented in Table 2.

In general, men and women were treated with similar strategies according to the 5 treatment groups. But across the treatment groups, women more often than men started a treatment strategy containing hydroxychloroquine [HCQ; HCQ monotherapy, MTX + HCQ, and HCQ + GC, but not MTX + sulfasalazine (SSZ) + HCQ)]. Men more often started a treatment strategy containing SSZ and/or MTX (SSZ monotherapy, MTX + SSZ, and MTX + GC). Men who started HCQ monotherapy had on average a lower baseline

Personal non-commercial use only. The Journal of Rheumatology Copyright $\odot$ $)$ 2018. All rights reserved 
Table 1. Baseline characteristics of men and women. Mean (SD) reported unless otherwise specified.

\begin{tabular}{|c|c|c|c|c|c|}
\hline \multirow[t]{2}{*}{ Characteristics } & \multicolumn{2}{|c|}{$\begin{array}{c}\text { Men, } \mathrm{n}=1142 \\
(21 \%)\end{array}$} & \multicolumn{2}{|c|}{$\begin{array}{c}\text { Women, } \mathrm{n}=4393 \\
(79 \%)\end{array}$} & \multirow[t]{2}{*}{$\mathrm{p}$} \\
\hline & Values & $\mathrm{N}$ & Values & $\mathrm{N}$ & \\
\hline Age at first visit, yrs & $52.0(14.9)$ & 1139 & $46.9(13.9)$ & 4371 & $<0.001$ \\
\hline $\mathrm{BMI}, \mathrm{kg} / \mathrm{m}^{2}$ & $27.1(4.8)$ & 730 & $27.0(6.6)$ & 2500 & 0.647 \\
\hline RF-positive, $\%$ & 70.6 & 1104 & 75.5 & 4270 & 0.001 \\
\hline ACPA-positive, $\%$ & 66.3 & 656 & 70.8 & 2363 & $<0.001$ \\
\hline Smoking, $\%$ & & 900 & & 3832 & $<0.001$ \\
\hline Never & 62.3 & & 88.5 & & \\
\hline Previous smoker & 14.2 & & 5.2 & & \\
\hline Current smoker & 23.0 & & 6.3 & & \\
\hline $\begin{array}{l}\text { Symptom duration at diagnosis, } \\
\text { mos, median (IQR) }\end{array}$ & $10.3(3.9-23.9)$ & 1142 & $12.3(5.9-34.8)$ & 4393 & $<0.001$ \\
\hline $\begin{array}{l}\text { Time to treatment initiation from } \\
\text { diagnosis, days }\end{array}$ & $4.3(14.8)$ & 1142 & $3.8(14.0)$ & 4393 & 0.009 \\
\hline HAQ, $0-3$ & $0.96(0.69)$ & 897 & $1.1(0.68)$ & 3668 & $<0.001$ \\
\hline DAS & $3.5(1.1)$ & 753 & $3.7(1.0)$ & 2689 & $<0.001$ \\
\hline DAS 28 & $5.5(1.4)$ & 817 & $5.8(1.4)$ & 2933 & $<0.001$ \\
\hline $\mathrm{ESR}, \mathrm{mm} / \mathrm{h}$ & $46.2(32.2)$ & 1017 & $57.4(33.7)$ & 3809 & $<0.001$ \\
\hline CRP, mg/l, median (IQR) & $24(11-50)$ & 869 & $21(9-45)$ & 3391 & $<0.001$ \\
\hline VAS patient global, $0-100$ & $53.5(23.0)$ & 896 & $55.0(22.0)$ & 3295 & 0.091 \\
\hline Ritchie articular index, $0-78$ & $8.6(6.4)$ & 1061 & $10.2(6.6)$ & 4075 & $<0.001$ \\
\hline SJC, $0-44$ & $7.2(7.4)$ & 1062 & $6.5(6.5)$ & 4079 & 0.027 \\
\hline TJC 28, 0-28 & $10.9(8.7)$ & 1129 & $12.6(9.3)$ & 4347 & $<0.001$ \\
\hline SJC $28,0-28$ & $6.4(6.2)$ & 1133 & $5.8(5.5)$ & 4368 & 0.021 \\
\hline
\end{tabular}

BMI: body mass index; RF: rheumatoid factor; ACPA: anticitrullinated protein antibodies; IQR: interquartile range; HAQ: Health Assessment Questionnaire; DAS: Disease Activity Score; DAS28: 28-joint DAS; ESR: erythrocyte sedimentation rate; CRP: C-reactive protein; VAS: visual analog scale; SJC: swollen joint count; SJC28: 28-joint SJC; TJC28: 28-joint tender joint count.

DAS than men starting different treatments, as well as lower than women who started HCQ. Women who started MTX monotherapy on average had a slightly higher baseline DAS than women starting monotherapy with other csDMARD. In the group starting with combination therapy of $>1$ csDMARD and a GC, no sex differences were present. In addition, because HCQ might be preferentially prescribed to pregnant women or to women with a desire to conceive, we assessed whether HCQ was more often prescribed to women of childbearing age. It was found that women $\geq 50$ years of age were less often prescribed HCQ $(27.5 \%$ vs $36.8 \%$ for women $<50 \mathrm{yrs})$. However, the same was found for men ( $14.9 \%$ for men $\geq 50$ years vs $23.8 \%$ for men $<50$ yrs).

Further, because medication use differed slightly among countries, initial treatment of men and women was shown per country, for countries contributing at least 100 patients (Supplementary Tables 2-9, available with the online version of this article). Specifically, in contrast to the overall findings, women compared to men did not receive more often HCQ monotherapy in Portugal or in the UK, not more often combination of MTX + HCQ in the UK, and not more often combination of HCQ + GC in Mexico or in the UK. Last, the proportion of patients receiving GC monotherapy differed for some countries, with more men in Mexico and Portugal and more women in the Netherlands receiving GC monotherapy.
Treatment switch. Time to switch medication (i.e., the time to decide that the first treatment step had failed) was shorter in women [median 175 (IQR 91-384) days or 25 (IQR 13-55) weeks, $\mathrm{n}=2756$ ] than in men [median 200 (IQR 98-400) days or 29 (IQR 14-57) weeks, $\mathrm{n}=647$ ]. In total, 2146 patients (1637 women, 495 men) did not switch treatment before the end of followup and were censored [median followup time 336 (IQR 132-708) days or 48 (IQR 19-101) weeks for women and 387 (IQR 187-733) days or 55 (IQR 27-105) weeks for men]. Cox regression analyses on the effect of sex on time from the initial treatment to a next treatment step confirmed that women were slightly more likely to switch treatment than men (HR 1.22, 95\% CI 1.12-1.33). However, after adjusting for age, RF, ACPA, symptom duration at diagnosis, country, BMI, smoking (all at baseline), and DAS as time-varying covariate, the effect disappeared (HR 1.02, 95\% CI 0.93-1.12).

Treatment response. Analyses on the effects of sex on treatment response revealed that for most treatment groups at baseline, women had a slightly higher DAS $(\beta 0.18,95 \%$ CI $0.13-0.24)$ and HAQ $(\beta 0.16,95 \%$ CI $0.12-0.19)$ for all treatment groups combined (Supplementary Table 10, available with the online version of this article). The interaction term between sex and time was statistically significant for the DAS outcome over time $(\mathrm{p}=0.011)$. However, after Personal non-commercial use only. The Journal of Rheumatology Copyright $\subset$ 2018. All rights reserved. 
Table 2. Initial treatment of men and women.

\begin{tabular}{|c|c|c|c|c|}
\hline \multirow[t]{2}{*}{ Variables } & \multicolumn{2}{|c|}{ Men, $n=1142$} & \multicolumn{2}{|c|}{ Women, $\mathrm{n}=4393$} \\
\hline & $\mathrm{n}(\%)$ & DAS*, mean (SD) & $\mathrm{n}(\%)$ & DAS*, mean (SD) \\
\hline csDMARD monotherapy & $421(36.9)$ & $3.4(1.1)$ & $1804(41.2)$ & $3.6(1.0)$ \\
\hline MTX & $248(58.9)$ & $3.6(1.2)$ & $983(54.5)$ & $3.8(1.0)$ \\
\hline SSZ & $83(19.7)$ & $3.2(1.1)$ & $181(10.0)$ & $3.3(0.9)$ \\
\hline HCQ & $80(19.0)$ & $2.8(0.8)$ & $597(33.1)$ & $3.4(0.9)$ \\
\hline Other & $10(2.4)$ & - & $43(2.4)$ & - \\
\hline GC monotherapy & $103(9.0)$ & $3.3(0.9)$ & $252(5.7)$ & $3.3(0.9)$ \\
\hline \multicolumn{5}{|l|}{ csDMARD combination } \\
\hline therapy & $233(20.4)$ & $3.5(1.1)$ & 947 (21.6) & $3.9(1.0)$ \\
\hline MTX + HCQ & $95(40.8)$ & $3.3(1.0)$ & $554(57.9)$ & $3.9(1.0)$ \\
\hline MTX + SSZ & $70(30.0)$ & $3.6(1.0)$ & $192(20.1)$ & $3.7(1.0)$ \\
\hline $\mathrm{MTX}+\mathrm{SSZ}+\mathrm{HCQ}$ & $40(17.2)$ & $3.1(0.7)$ & $122(12.8)$ & $3.5(0.9)$ \\
\hline $\mathrm{SSZ}+\mathrm{HCQ}$ & $19(8.2)$ & $3.3(0.9)$ & $48(5.0)$ & $3.5(0.9)$ \\
\hline MTX + LEF & $5(2.2)$ & $4.8(0.7)$ & $24(2.5)$ & $3.8(1.2)$ \\
\hline Other & $4(1.7)$ & - & $7(0.7)$ & - \\
\hline csDMARD + GC & $271(23.7)$ & $3.7(1.2)$ & $928(21.2)$ & $3.6(1.0)$ \\
\hline $\mathrm{MTX}+\mathrm{GC}$ & $226(83.4)$ & $3.7(1.1)$ & $705(76.0)$ & $3.6(1.0)$ \\
\hline $\mathrm{HCQ}+\mathrm{GC}$ & $21(7.8)$ & $3.8(1.7)$ & $136(14.8)$ & $3.6(0.9)$ \\
\hline $\mathrm{SSZ}+\mathrm{GC}$ & $17(6.3)$ & $3.6(1.3)$ & $53(5.7)$ & $3.8(1.0)$ \\
\hline $\mathrm{LEF}+\mathrm{GC}$ & $4(1.5)$ & $3.8(1.2)$ & $26(2.8)$ & $3.4(1.1)$ \\
\hline Other & $3(1.1)$ & - & $8(0.9)$ & - \\
\hline \multicolumn{5}{|l|}{ Combination csDMARD } \\
\hline$+\mathrm{GC}$ & $114(10.0)$ & $3.6(1.1)$ & $452(10.3)$ & $3.9(1.0)$ \\
\hline $\mathrm{MTX}+\mathrm{HCQ}+\mathrm{GC}$ & $48(42.1)$ & $3.5(1.2)$ & $205(45.4)$ & $3.8(1.0)$ \\
\hline $\mathrm{MTX}+\mathrm{SSZ}+\mathrm{GC}$ & $26(22.8)$ & $3.6(0.9)$ & $111(24.6)$ & $3.9(1.0)$ \\
\hline $\mathrm{MTX}+\mathrm{SSZ}+\mathrm{HCQ}+\mathrm{GC}$ & $20(17.5)$ & $3.4(0.8)$ & $74(16.4)$ & $3.6(1.0)$ \\
\hline $\mathrm{SSZ}+\mathrm{HCQ}+\mathrm{GC}$ & $13(11.4)$ & $3.4(0.9)$ & $32(7.1)$ & $3.6(1.0)$ \\
\hline $\mathrm{MTX}+\mathrm{LEF}+\mathrm{GC}$ & $4(3.5)$ & $3.1(1.2)$ & $9(2.0)$ & $4.3(1.1)$ \\
\hline Other & $3(2.6)$ & - & $21(4.6)$ & - \\
\hline
\end{tabular}

* DAS based on the non-imputed database. csDMARD: conventional synthetic disease-modifying antirheumatic drugs; MTX: methotrexate; SSZ: sulfasalazine; HCQ: hydroxychloroquine; LEF: leflunomide; GC: glucocorticoid; DAS: Disease Activity Score.

stratification for sex, differences in improvement in DAS over time proved to be negligible between men $(\beta-0.69,95 \%$ $\mathrm{CI}-0.75$ to -0.62 per yr) and women $(\beta-0.58,95 \% \mathrm{CI}-0.62$ to -0.55 per yr), and the change in HAQ over time was not different between men and women ( $p=0.200$; Table 3$)$.

When analyses were repeated in the subgroups of the different medication strategies, the interaction term between sex and time was statistically significant for the DAS outcome over time only in the csDMARD combination therapy subgroup $(\mathrm{p}=0.014)$, but analyses stratified for sex revealed no clinically relevant differences in improvement in DAS over time ( $\beta-0.89,95 \% \mathrm{CI}-1.07$ to -0.71$)$ for men and ( $\beta-0.59,95 \%$ CI -0.67 to -0.51 for women per yr; Table 3$)$. For all other treatment strategies, there were no differences in DAS and HAQ improvement between men and women. Detailed outcomes for the subgroup analyses on the effect of sex on treatment response are shown in Supplementary Tables 10 and 11 (available with the online version of this article). When subanalyses were performed within the strategy subgroups for individual medication combinations, there were no sex differences in treatment response as measured by DAS and HAQ (Supplementary Table 12, available with the online version of this article).

\section{DISCUSSION}

In our study based on real-world clinical data, we aimed to assess whether men and women with RA are treated differently and whether the response to various therapies differs between them. Previously, a concern has been raised that women with RA might be treated less aggressively than men. For instance, a study in the NOR-DMARD registry reported lower access to biologic (b-) DMARD for females in the period 2000-2003 but not in more recent periods (2009-2011) ${ }^{17}$. Another study in the QUEST-RA database found no significant differences in the proportion of men and women taking prednisone, MTX, or bDMARD and showed similar delays of initiation to therapy ${ }^{7}$. In our current study, we found that women had, at the start of treatment, slightly longer symptom duration than men, and more often started treatment with HCQ as monotherapy (women $33 \%$ vs men $19 \%$ ), in combination with MTX (58\% vs $41 \%$ ), or with a GC $(15 \%$ vs $8 \%)$, whereas men more often started treatment

Personal non-commercial use only. The Journal of Rheumatology Copyright $\subset$ $\subset$ 2018. All rights reserved 
Table 3. Evolution of HAQ and DAS over time in men and women ${ }^{\mathrm{a}}$.

\begin{tabular}{|c|c|c|c|c|}
\hline Variables & $\begin{array}{c}\text { HAQ } \\
\mathrm{p}^{\mathrm{b}}\end{array}$ & Men, $\beta(95 \%$ CI $)$ & $\begin{array}{c}\text { DAS } \\
\text { Women, } \beta(95 \% \mathrm{CI})\end{array}$ & $\mathrm{p}^{\mathrm{b}}$ \\
\hline All patients, $n$ & & 1142 & 4393 & \\
\hline Sex and followup time interaction & 0.200 & - & - & 0.011 \\
\hline Followup time, yrs & & $-0.69(-0.75$ to -0.62$)$ & $-0.58(-0.62$ to -0.55$)$ & \\
\hline csDMARD combination therapy, $\mathrm{n}$ & & 233 & 947 & \\
\hline Sex and followup time interaction & 0.706 & - & - & 0.014 \\
\hline Followup time, yrs & & $-0.89(-1.07$ to -0.71$)$ & $-0.59(-0.67$ to -0.51$)$ & \\
\hline csDMARD monotherapy, n & & 421 & 1804 & \\
\hline Sex and followup time interaction & 0.453 & - & - & 0.178 \\
\hline $\mathrm{GC}, \mathrm{n}$ & & 103 & 252 & \\
\hline Sex and followup time interaction & 0.283 & - & - & 0.462 \\
\hline csDMARD + GC, n & & 271 & 928 & \\
\hline Sex and followup time interaction & 0.419 & - & - & 0.263 \\
\hline csDMARD combination + GC, $\mathrm{n}$ & & 114 & 452 & \\
\hline Sex and followup time interaction & 0.848 & - & - & 0.931 \\
\hline
\end{tabular}

${ }^{\text {a }}$ Results stem from linear multivariable mixed model analyses adjusted for age, RF, ACPA, symptom duration at diagnosis, BMI, smoking, and country. Different models were constructed for all patients and then for treatment subgroups. Regression coefficients represent the units of change in the outcome per unit of time, in this case, per year. ${ }^{\mathrm{b}} \mathrm{P}$ values are shown only for the interactions between sex and time. In the presence of a statistically significant interaction, results are stratified by sex, and the evolution of DAS over time is shown for men and women separately. HAQ: Health Assessment Questionnaire; DAS: Disease Activity Score; csDMARD: conventional synthetic disease-modifying antirheumatic drugs; GC: glucocorticoids; RF: rheumatoid factor; ACPA: anticitrullinated protein antibodies; BMI: body mass index.

with MTX and/or SSZ. This indeed suggests a slightly less aggressive approach in women compared to men: HCQ monotherapy reportedly has only a small effect in reducing the swollen joint count, and its effects on delaying joint damage are smaller compared to $\mathrm{SSZ}^{18,19}$. We found that HCQ was prescribed to male patients mostly if they had low disease activity, but women were treated with HCQ or other csDMARD irrespective of disease activity. It has to be said, though, that sex differences in medication use were slightly country-dependent. This could be influenced by political, economic, or cultural factors that might differ per country but fall beyond the scope of this article.

We found a slightly worse response to treatment for women than for men, but the difference was small (decrease in DAS, when extrapolated to a year, differed by 0.1 point), and appeared to be based on a statistically significant difference in DAS improvement only for initial treatment with csDMARD combination therapy. Also, this difference between men and women was, in clinical terms, negligible.

It could be argued that women more often receive HCQ because HCQ is considered safe during pregnancy, in contrast to, for example, MTX, and might therefore be prescribed to pregnant women or to women with a desire to conceive ${ }^{20}$. It was indeed observed that women $\leq 50$ years of age more often received HCQ; however, this effect was the same for men and therefore does not seem to be related to (wish for) pregnancy. Moreover, we assessed whether age $(<50 \mathrm{yrs}$ or $\geq 50 \mathrm{yrs}$ ) was an effect modifier for the association between sex and treatment response, but we did not find a different response to treatment for these different age categories.

Previous studies in different registers have reported higher response rates in men compared to women for several treatment strategies with bDMARD ${ }^{8,9,21}$. However, the selection of patients in these studies differs from our current study, in which initial treatment in newly diagnosed patients with RA were compared. An analysis in the BeSt study, a randomized clinical trial, identified male sex as a predictor of MTX efficacy, which we did not find in our current study $^{22}$. This might be due to differences in patient selection, such as a DAS 1 point higher at baseline in the BeSt study, or to differences in, for example, dosing schedules in a trial setting compared to daily clinical practice.

It has been suggested that a higher level of disease activity in women is inherent to the components of disease activity composite scores, rather than to differences in specifically rheumatic activity in men and women ${ }^{7}$. For example, erythrocyte sedimentation rate levels are usually higher in women than in men, especially in older women ${ }^{7,23}$, and women often report more symptoms and pain in questionnaires compared to men ${ }^{1,7}$. In addition, men may have a tendency to underreport problems, as has been described with regard to the $\mathrm{HAQ}^{24}$. This may explain part of the previously found sex differences in response to treatment.

We also found that women had a shorter time to switch medication than men. However, after adjusting for several confounders including disease activity over time, sex no longer determined the likelihood to switch medication.

Personal non-commercial use only. The Journal of Rheumatology Copyright @ (2018. All rights reserved. 
Our study has several potential limitations. We compared different treatment combinations but did not take into account differences in dosing schedules between patients. Although dosing schedules for many drugs are fixed, this may still influence outcomes. Moreover, because this is an observational study, associations between variables should not be interpreted in a causal manner. Further, because the prescription of medication is not randomized, several known and unknown variables may have influenced the choice of the physician to prescribe certain medication (confounding by indication). Confounding by indication may also have influenced the response to treatment. Because only part of the potential confounders is known and measured, it is always possible that residual (unmeasured) confounding exists.

Our study shows that men and women are prescribed different treatments: women more often started HCQ, as monotherapy or in combination with MTX or a GC, whereas men more often started treatment with MTX and/or SSZ. Although we found a statistically significantly worse response to treatment with csDMARD combination therapy (decrease in DAS but not HAQ) in women compared to men, these differences between the sexes were clinically negligible. In general, although the initial treatments prescribed to men and women may differ, it appears that the clinical response is similar for both sexes.

\section{ONLINE SUPPLEMENT}

Supplementary material accompanies the online version of this article.

\section{REFERENCES}

1. Sherrer YS, Bloch DA, Mitchell DM, Roth SH, Wolfe F, Fries JF. Disability in rheumatoid arthritis: comparison of prognostic factors across three populations. J Rheumatol 1987;14:705-9.

2. Jawaheer D, Lum RF, Gregersen PK, Criswell LA. Influence of male sex on disease phenotype in familial rheumatoid arthritis. Arthritis Rheum 2006;54:3087-94.

3. Da Silva JA, Larbre JP, Spector TD, Perry LA, Scott DL, Willoughby DA. Protective effect of androgens against inflammation induced cartilage degradation in male rodents. Ann Rheum Dis 1993;52:285-91

4. Ishizuka M, Hatori M, Suzuki T, Miki Y, Darnel AD, Tazawa C, et al. Sex steroid receptors in rheumatoid arthritis. ClinSci 2004;106:293-300.

5. Kuiper S, van Gestel AM, Swinkels HL, de Boo TM, Da Silva JA, van Riel PL. Influence of sex, age, and menopausal state on the course of early rheumatoid arthritis. J Rheumatol 2001;28:1809-16.

6. Wilder RL. Adrenal and gonadal steroid hormone deficiency in the etiopathogenesis of rheumatoid arthritis. J Rheumatol Suppl. 1996 Jul;44:10-2.

7. Sokka T, Toloza S, Cutolo M, Kautiainen H, Makinen H, Gogus F, et al; QUEST-RA Group. Women, men, and rheumatoid arthritis: analyses of disease activity, disease characteristics, and treatments in the QUEST-RA study. Arthritis ResTher 2009;11:R7.

8. Hyrich KL, Watson KD, Silman AJ, Symmons DP; British Society for Rheumatology Biologics Register. Predictors of response to anti-TNF-alpha therapy among patients with rheumatoid arthritis: results from the British Society for Rheumatology Biologics Register. Rheumatology 2006;45:1558-65.
9. Jawaheer D, Olsen J, Hetland ML. Sex differences in response to anti-tumor necrosis factor therapy in early and established rheumatoid arthritis - results from the DANBIO registry. J Rheumatol 2012;39:46-53.

10. Asikainen J, Nikiphorou E, Kaarela K, Lindqvist E, Hakkinen A, Kautiainen $\mathrm{H}$, et al. Is long-term radiographic joint damage different between men and women? Prospective longitudinal data analysis of four early RA cohorts with greater than 15 years follow-up. Clin Exp Rheumatol 2016;34:641-5.

11. Forslind K, Hafstrom I, Ahlmen M, Svensson B; BARFOT Study Group. Sex: a major predictor of remission in early rheumatoid arthritis? Ann Rheum Dis 2007;66:46-52.

12. Hallert E, Thyberg I, Hass U, Skargren E, Skogh T. Comparison between women and men with recent onset rheumatoid arthritis of disease activity and functional ability over two years (the TIRA project). Ann Rheum Dis 2003;62:667-70.

13. Bergstra SA, Machado PM, van den Berg R, Landewe RB, Huizinga TW. Ten years of METEOR (an international rheumatoid arthritis registry): development, research opportunities and future perspectives. Clin Exp Rheumatol 2016;5 Suppl 101:S87-90.

14. van der Heijde DM, van 't Hof MA, van Riel PL, Theunisse LA, Lubberts EW, van Leeuwen MA, et al. Judging disease activity in clinical practice in rheumatoid arthritis: first step in the development of a disease activity score. Ann Rheum Dis 1990;49:916-20.

15. Fries JF, Spitz P, Kraines RG, Holman HR. Measurement of patient outcome in arthritis. Arthritis Rheum 1980;23:137-45.

16. Schafer JL. Analysis of incomplete multivariate data. Boca Raton: Chapman \& Hall/CRC; 1997.

17. Putrik P, Ramiro S, Lie E, Keszei AP, Kvien TK, van der Heijde D, et al. Less educated and older patients have reduced access to biologic DMARDs even in a country with highly developed social welfare (Norway): results from Norwegian cohort study NOR-DMARD. Rheumatology 2016;55:1217-24.

18. Faarvang KL, Egsmose C, Kryger P, Podenphant J, Ingeman-Nielsen M, Hansen TM. Hydroxychloroquine and sulphasalazine alone and in combination in rheumatoid arthritis: a randomised double blind trial. Ann Rheum Dis 1993;52:711-5.

19. van der Heijde DM, van Riel PL, Nuver-Zwart IH, van de Putte LB. Sulphasalazine versus hydroxychloroquine in rheumatoid arthritis: 3-year follow-up. Lancet 1990;335:539.

20. Gerosa M, Schioppo T, Meroni PL. Challenges and treatment options for rheumatoid arthritis during pregnancy. Expert Opin Pharmacother 2016;17:1539-47.

21. Couderc M, Gottenberg JE, Mariette X, Pereira B, Bardin T, Cantagrel A, et al; Club Rhumatismes et Inflammations. Influence of gender on response to rituximab in patients with rheumatoid arthritis: results from the Autoimmunity and Rituximab registry. Rheumatology 2014;53:1788-93.

22. Wessels JA, van der Kooij SM, le Cessie S, Kievit W, Barerra P, Allaart CF, et al; Pharmacogenetics Collaborative Research Group. A clinical pharmacogenetic model to predict the efficacy of methotrexate monotherapy in recent-onset rheumatoid arthritis. Arthritis Rheum 2007;56:1765-75.

23. Miller A, Green M, Robinson D. Simple rule for calculating normal erythrocyte sedimentation rate. Br Med J 1983;286:266.

24. van den Ende CH, Breedveld FC, Dijkmans BA, Hazes JM. The limited value of the Health Assessment Questionnaire as an outcome measure in short term exercise trials. J Rheumatol $1997 ; 24: 1972-7$ 